the tubercle bacilli. It is generally conceded by leprologists, like Hansen, Schlesinger, Darling, ${ }^{22}$ Laehr, Impey ${ }^{23}$ and others, that in chronic, old cases of leprosy neuritis, the bacilli of leprosy cannot be demonstrated, and in a case of fifty-four years' standing, like ours, it is almost impossible to demonstrate them. On the other hand, leprosy and syringomyelia may be combined, as in the case of Gerber and Matzenauer, ${ }^{2+}$ and nerve thickening may be present in unquestionable cases of syringomyelia, as in cases of Steudener ${ }^{25}$ and Langhans, ${ }^{26}$ which were intra vitam diagnosed as leprosy and as such interpreted. At any rate, absence of this sign, or even of leprous bacilli, cannot shake the diagnosis of leprosy, in the presence of numerous other signs, as total anesthesia of all four limbs, of the conjunctivae, absence of scars on the stumps, involvement of the upper facial nerves, absence of atrophies typical of syringomyelia, of fibrillary twitchings, of electrical changes, with the presence of typical changes in the bones.

All these negative and positive signs, their multiplicity, as Laehr ${ }^{12}$ puts it, are very characteristic of leprosy, and are all present in our patient.

The question arises, Which of these "multiple" signs ought to be considered characteristic for leprosy?

Of bone changes we spoke already, and we should like to say a few words in regard to another sign which, in our opinion, is highly characteristic for leprosy. Here belongs the topography of the sensory disturbances, the distribution of the anesthesias. These affected, in our patient, all the four extremities, and gave a similar picture in all of the eight cases of Marestang, ${ }^{18}$ and is pictured by Russy ${ }^{27}$ in Marie's collective work as typical for peripheral lesions of leprous nature.

In syringomyelia, the upper limbs, as a rule, are involved, and the lower limbs only in the so-called lumbosacral form, when the cavities involve the lower portion of the spinal cord. In cases of syringomyelia in which the cavities are extensive, all along the spinal cord, medulla, etc., as in cases of Hoffman, ${ }^{28}$ Spiller, ${ }^{29}$ Knoblauch ${ }^{30}$ and Steudener, ${ }^{25}$ the anesthesia will involve not only the upper and lower limbs, but also the rest of the body. Cases of syringomyelia in which the sensory disorders resemble those in our patient, being confined to the peripheral portions of all four limbs, we did not find recorded, except one case cited by Bruhl. ${ }^{31}$

But the patient in this case had an ectropion, profound trophic disturbances, as perforated ulcers, etc., which facts speak rather for leprosy than syringomyelia. In fact, it would be impossible to give an anatomic reason for the presence of sensory anomalies on the four limbs only, unless we accept two cavities, one in the cervical, and the other in the lumbar

22. Darling: The Journal A. M. A., September, 1910, p. 912.

23. Impey: The Noncontagious Nature of Anesthetic Leprosy, Med. Week., 1897 , p. 485 .

24. Matzenauer and Gerber: Lepra und Syringomyelie in Obersteiner's Arbeiten, ix, 1902.

25. Steudener: De Lepra Anesthetica sive mutilans, Halle, 1867; abstr., Virchow-Hirsh's Jahresb. ü. die Leist. u. Fortsch. d. ges. Med., 1868 , p. 404.

26. Langhans: Zur Casuistik der Rückenmarkaffectionen, Virchows Arch. f. path. Anat., 1875, 1xiv, 169.

27. Russy, in Pierre Marie: La Pratique Neurologique, Paris, 1911,

p. 349. 28 . Hoffman: Zur Lehre von der Syringomyelie, Deutsch. $Z$ tschr. f. Nervenh., 1892 , iii.

29. Spiller: Syringomyelia and Syringobulbia, Brit. Med. Jour., Oct. 20 , 1906, p. 1017.

30. Knoblauch: Krankheiten des Centralnervensystems, 1909, p. 154 31. Bruhl: Contribution à l'étude de la syringomyélie, Paris, 1890, p. 154 (Case 8 ). region, separated by a healthy spinal cord. If such a possibility is mentioned in the literature (Bruhl), then we ought to have symptoms of the lumbosacral form of syringomyelia, as described by Schlesinger ${ }^{8}$ and Herbert, ${ }^{6}$ but which are absent in our patient.

Therefore, we must consider the presence of anesthesias on the four limbs typical for leprosy, especially if additional signs be present, as bone changes, upper facial paralysis, total loss of reflexes, etc. As all these signs were present in our patient, we are fully justified in diagnosing our case as anesthetic leprosy.

31 North State Street-Cook County Hospital.

\section{FOREIGN BODY IN THE LUNG}

REPORT OF A CASE IN WHICH THE PRIMARY DIAGNOSIS WAS SUGGESTED BY A BLOOD EXAMINATION *

GEORGE L. RICHARDS, M.D.

Otologist and Laryngologist, L̈nion and St. Anne's Hospitals

FALL RIVER, MASS.

A man, aged 25, with negative family history, from some time in early childhood up to the time of coming under observation had occasional attacks of asthmatic breathing, bronchitis and chills. Since 1910, occasional chills followed by fever of 101 to 103 and lasting but a few hours had been the particular symptom. The intervals between the attacks had varied from a few days to a few weeks, and immediately after the attack, and also on the day following, the patient would feel perfectly well. He entered college in 1910. A lung examination by a general physician, on what date I am unable to find out, says that there was a little trouble near the right nipple line; but what this trouble was, was undetermined. He had an occasional whistle on breathing, which, during these years, was thought to be due to chronic asthma. July 12, 1913, a local physician advised that he have a blood count, which showed a white count of 16,120 with an increase of polymorphonuclears. Medicine was given at this time, but being no better, he was taken to a stomach specialist who suggested a Roentgen examination. This examination was made by the fluoroscope only, and nothing abnormal was noticed. His mother then took him to a diagnostician in Boston, who looked the boy over carefully, but could find nothing particular the matter. He thought that whatever it was, it would pass away, as in the intervals and when examined by a physician he appeared to be in good condition. The mother, supposing the fluoroscopic examination was a complete Roentgen examination, stated to the physician that the Roentgen examination was negative.

Another blood count was made, Feb. 28, 1914, when the white count was 12,200 with slight increase of polymorphonuclears. In July, 1914, the patient went to Europe, but on the way over on the steamer had two chills, and again a chill in Florence. In Florence he was taken to a physician who suggested that there might be some trouble in the right lung, but was unable to determine just what it was. These chills, as stated above, lasted from two and one-half to three hours, and were followed by a temperature of from 101 to 103, and, as before, he appeared perfectly well the day following. He was brought to me, Nov. 30,

* Presented before the Thirty-Seventh Annual Meeting of - the American Laryngological Association, Niagara Falls, June 3, 1915 . 
1914, to find out whether he was fitted to work in a caisson in one of the New York subways, as he had been trained for engineering work. I had a blood examination made at this time, and found a leukocytosis of something over 12,000. I went over his chest and general condition and found that he had occasional twinges of pain a little below and slightly to the left of the right nipple, but did not detect anything out of the way, nor did I then suggest a Roentgen examination. I told him he could probably go on with the work desired. $\mathrm{He}$ went to New York to see about his place, but had a severe attack and chill the first day he was there, and immediately gave up and came home without making any attempt to get the job. He did not report to me, however, until several days later, when he appeared to be all right. $\mathrm{He}$ had had another attack since his return to Fall River, but less severe, and was coughing slightly. I had another blood count made, this time finding whites 12,480 , with an increase of polymorphonuclears to 88 per cent. A search was also. made for typhoid by the Widal reaction, and for tuberculosis from the little sputum we were able to obtain; the blood also

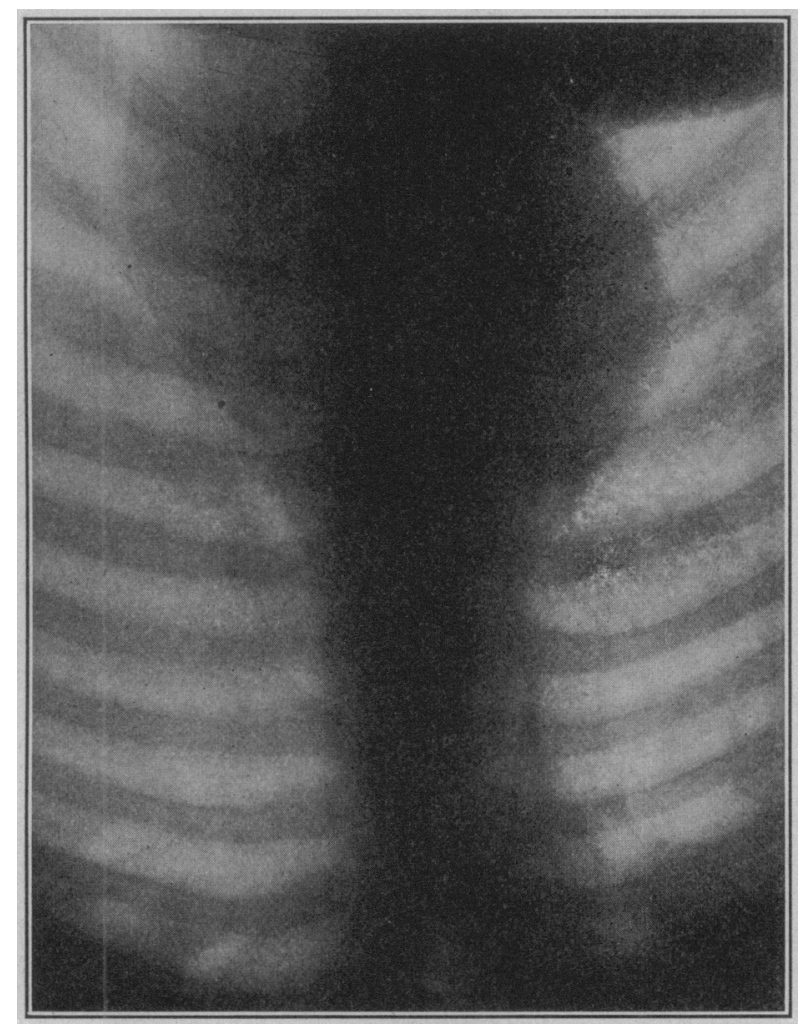

Fig. 1.-Roentgenogram, showing tack. ably more or less encapsulated, was probably in a cavity, and that between the head of the tack and the main bronchus there might be quite a band of adhesive or inflammatory tissue, which opinion was confirmed by the hearing of an occasional whistle on auscultation. I had in mind such a case as is described in the English edition of Brünings' Book on Bronchoscopy, p. 353. I took the patient to Dr. Chevalier Jackson, Pittsburgh, to verify the diagnosis and to remove the tack.

Two roentgenograms were taken in Pittsburgh; each verified the diagnosis as to location, and as to the probable narrowing of the bronchus between its location and the main bronchus. Dr. Jackson, after previcus administration of morphin and atropin, under cocain anesthesia, and with the aid of the upper lobe bronchus forceps, after dilatation of the strictured bronchus, removed the $t$ :ck. At no time could it be seen by direct inspection. Dr. Jackson was able, however, so far to feel within the bronchus as to locate the tack first with a probe. After several attempts the head was grasped and removed. The point of the tack, however, was not forthcoming; the head was was examined for malarial organisms, but with negative results.

On thinking over the case, it struck me as being rather peculiar that we should have here an apparently healthy young man with occasional attacks of pain, occasional attacks of chills and fever of very short duration, with only a suggestion of a cough, but with a moderate steady leukocytosis and with no definite physical signs. At this moment it suddenly dawned on me for the first time that the symptoms were more suggestive of a foreign body in the right bronchus than anything else, a foreign body in a cavity which probably filled up at times, causing absorption, and then emptying itself, remaining open a longer

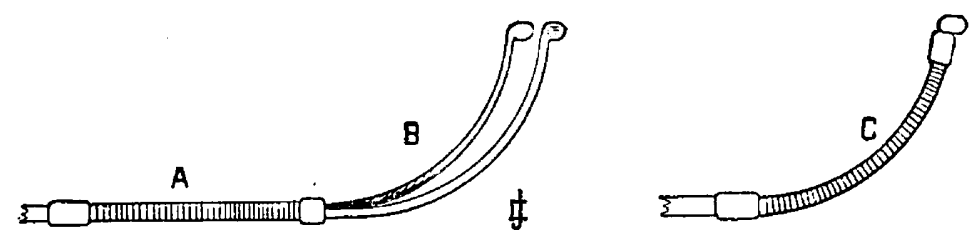

Fig. 2.-Jackson upper lobe hronchus forceps. much eroded and covered with oxidation products. It showed the probability that it had been in this position a long time, with the result that the tack had been so far rusted away and the oxidation products cast off sufficiently to separate the point of the tack from the head. Two portions of black, ironlike débris were removed. No reaction followed, and no chill or any further trouble with the lung has occurred since.

In the light of our present knowledge of this case, it is easy to ask why a roentgenogram was not taken, and the question is a proper one. Yet it did not occur to any one until the persistent low le!1kocytosis, together with the suggestion of bronchial asthma and the point of occasional pain, finally made the or shorter time. I therefore had a Roentgen examination made, which disclosed a tack in the right bronchus.

There is no history as to when the tack entered the lung. The patient does not remember to have ever swallowed anything of the kind. A review of the history of the case seems to show that very likely the tack was introduced many years before, as when it was finally removed, its condition was such as to justify this supposition. I assumed that it was prob- clinical picture so clear that I assumed there must be a foreign body, and had the roentgenogram made. The moral is, that in any case of possible trouble in the chest, abdomen or elsewhere not readily cleared up, the Roentgen ray should be used with the hope that it may aid in clearing the diagnosis. Again, foreign bodies which have been in the chest a long time and are unsuspected are probably far more common than any of us have yet ascertained. 